\title{
How Professionals Support Amateurs' Creativity Within the Brewing Community
}

\author{
Tiffany Knearem \\ Pennsylvania State University \\ University Park, PA \\ tak54@psu.edu
}

\section{John M. Carroll}

Pennsylvania State University

University Park, PA

jcarroll@psu.edu

\author{
Xiying Wang \\ Neurotrack \\ Redwood City, CA \\ jennwang404@gmail.com
}

\section{ABSTRACT}

Interest in artistry beer brewing has become increasingly popular over the past few decades. Within the brewing community, both professionals and amateurs engage their creativity when crafting their own beer. In this study, we are interested in understanding how members of the community support each other to be creative. Specifically, we investigated the forms of creativity support that professional crafters provide to amateurs. Our findings suggest that this creativity support holds an important role in enhancing creativity. We propose that technology design leverages the unique position of professionals to promote amateurs' creativity.

Permission to make digital or hard copies of part or all of this work for personal or classroom use is granted without fee provided that copies are not made or distributed for profit or commercial advantage and that copies bear this notice and the full citation on the first page. Copyrights for third-party components of this work must be honored. For all other uses, contact the owner/author(s)

CSCW '19 Companion, November 9-13, 2019, Austin, TX, USA

๑) 2019 Copyright held by the owner/author(s).

ACM ISBN 978-1-4503-6692-2/19/11.

https://doi.org/10.1145/3311957.3359446 
Table 1: Participant Demographics

\begin{tabular}{llll}
\hline Participant & Gender & Age & Years brewing \\
\hline AB1 & Male & $40 \mathrm{~s}$ & $10+$ \\
AB2 & Male & $60 \mathrm{~s}$ & $20+$ \\
AB3 & Male & $60 \mathrm{~s}$ & $30+$ \\
AB4 & Male & $40 \mathrm{~s}$ & $15+$ \\
AB5 & Male & $50 \mathrm{~s}$ & $30+$ \\
AB6 & Male & $20 \mathrm{~s}$ & 1 \\
AB7 & Male & $20 \mathrm{~s}$ & 1 \\
AB8 & Male & $30 \mathrm{~s}$ & $10+$ \\
AB9 & Female & $30 \mathrm{~s}$ & $10+$ \\
AB10 & Male & $20 \mathrm{~s}$ & $5+$ \\
PRO1 & Male & $50 \mathrm{~s}$ & $2 \mathrm{AB} / 30+\mathrm{PRO}$ \\
PRO2 & Male & $40 \mathrm{~s}$ & $0 \mathrm{AB} / 20+\mathrm{PRO}$ \\
PRO3 & Male & $30 \mathrm{~s}$ & $3 \mathrm{AB} / 5 \mathrm{PRO}$ \\
PRO4 & Male & $20 \mathrm{~s}$ & $0 \mathrm{AB} / 5 \mathrm{PRO}$ \\
PRO5 & Male & $30 \mathrm{~s}$ & $2 \mathrm{AB} / 8+\mathrm{PRO}$ \\
\hline AB connotes amateur brewer; PRO connotes
\end{tabular}

professional brewer

Table 2: Data Collection and Analysis

\begin{tabular}{ll}
\hline Interviews & 60-90 minutes \\
Location & Convenient for participant \\
Recorded & Fully transcribed \\
Coded & Comparative analysis [6] \\
\hline
\end{tabular}

\section{ACM Reference Format:}

Tiffany Knearem, Xiying Wang, and John M. Carroll. 2019. How Professionals Support Amateurs' Creativity Within the Brewing Community. In 2019 Computer Supported Cooperative Work and Social Computing Companion Publication (CSCW' 19 Companion), November 9-13, 2019, Austin, TX, USA. ACM, New York, NY, USA, 5 pages. https://doi.org/10.1145/3311957.3359446

\section{INTRODUCTION AND RELATED WORK}

Craft brewing has experienced a revival in interest over the past few decades. Approximately 1.1 million Americans engaged in the activity as hobbyist brewers in 2017 [2]. In addition, the number of craft breweries in the United States has skyrocketed from around 3,800 in 2014 to over 7,000 at the end of 2018 [4]. The growth of the brewing community reflects a growing interest in artistry products that allow the crafters to express their uniqueness and creativity [3]. In this paper, creativity is the everyday production of novel and appropriate ideas to open-ended problems [1]. Specifically in brewing, it is expressed through experimentation with the making process, unconventional uses of tools, and innovations with recipes [7].

The brewing community is comprised of amateurs and professionals who share the practice of brewing beer, which is an example of what Wenger considers a community of practice [11]. Cultivating members into the practice is vital for the viability of the community [10], and may be one reason that professionals invest their resources into developing amateurs'. With the support of the professionals, the amateurs are more capable of being creative because they have a larger palette to choose from Prior work suggests that amateurs can also develop each other's creativity by showing others how to re-purpose items into hand-made tools [5], through collaboration and interpersonal support [8] as well as how-to documentation [9]. To further our understanding of support for creativity, we build on our prior work in peer-to-peer creativity support and home brewing [7] to examine how beer-making professionals develop amateur crafters' creativity.

We conducted an exploratory user study with five professional craft brewers who hold the title of head brewer at a commercial brewery and 10 amateur brewers who brew as their hobby. We investigated the following research questions: 1) How do professional craft brewers (e.g. head brew masters) support amateur crafters (e.g. non-professionals who make beer at home) to be creative within their shared domain of practice? 2) What strengths and assets do professionals bring to promote amateurs' creativity? In the remainder of this paper, we refer to non-professional brewers as amateurs and people who brew at a commercial brewery as professionals.

\section{METHODS}

We interviewed 10 amateur home brewers and five professional brewers (see Table 1). All participants were distributed across the East Coast of the United States and were members of the home brewing 


\section{PRO1}

"I placed a guy who is now the quality assurance manager at [well-known brewery]. He worked with me at my last brewery as an intern. The minute I laid eyes on him I knew he was intelligent. When he started talking about chemistry and microbiology, I was like, oh my god, dude. What we are doing here is so minuscule compared to what he had the potential to do."

(Male, brewing professionally for $30+$ years)

\section{PRO2}

"Some of our work ethic was passed down too... it was the whole get it done no matter what [ethic]. They [amateurs] were probably cursing my name the entire time they did the hard work. But then years later when they realized how important that was, and how much it affected them, then they'd call me up and say 'hey I remember that thank you!' I hired a guy in 2003, he left in 2005. He and I still talk. He will still talk about the work ethic that we instilled in him, that he's now instilled in all of the places that he's worked."

(Male, brewing professionally for $20+$ years)

\section{PRO5}

"Next up is AB10's IPA. We usually do [the collaboration] so that the home brew club can exhibit it. We'll give them a keg of it to pour at [a local festival]. AB10 will be able to send bottles to his family too. So I thought that's a cool way to do that. He'll help us choose the artwork [for the bottle]."

(Male, brewing professionally for $8+$ years)

\section{AB10}

"It was a lot of fun. It was cool to see the parallels between what I do at home and the way they do things there... It was a lot of the same kind of stuff that I do at home, just amplified."

(Male, brewing as an amateur for $5+$ years) community of practice. The amateurs were either current home brewers, or former home brewers who were still active in a home brew club. The professional brewers were all head brew masters who brewed professionally at a commercial craft brewery on the East Coast. All amateur brewers were recruited from either one local home brew club or through snowball sampling. The professional brewers were recruited by contacting craft breweries. See Table 2 for data collection and analysis.

\section{CREATIVITY SUPPORT FROM PROFESSIONALS}

Our study suggests that professional crafters support amateurs' creativity by leveraging their role as professionals. Overall, the professionals expressed willingness to provide support and also encouraged amateurs to further develop their skills and creative problem solving. We call this creativity support from professionals to amateurs. Professionals promoted amateurs' creativity in four ways: acting as a bridge to connect amateurs to other members of the brewing community, mentoring and supporting amateurs to improve their skills, training amateurs through lectures, workshops or competitions, and obtaining materials that may be difficult or expensive for amateurs to acquire otherwise. These four sources of support helped non-professionals to experiment and innovate with their craft.

\section{Bridging Connections}

Two of the more experienced professionals, PRO1 and PRO2, mentioned the value they found in using their connections to further amateurs' networks. For example, PRO1 (see sidebar) enjoyed leveraging his 30 years of professional experience to help talented amateur brewers connect with apprenticeships in professional brewing. He also supported newcomers to receive further training, learn new techniques, and reach a higher level of domain-relevant skill, all of which facilitated the newcomers to craft artistry beer in their own styles. For PRO2, he was proud to have instilled a strong work ethic into the amateurs. By connecting amateurs to entry-level work in his brewery, he supported them to understand the required concentration and dedication involved in beer making. For him, working hard promoted another side of creativity: that diligence was less-attractive yet equally important behind the scenes.

\section{Mentorship}

Many of our professional participants talked about mentoring as something they did to support amateur brewers to improve their skills. Professional-amateur brewing collaborations were a popular activity that was sponsored by the professional. In this collaboration, the professional would invite an amateur home brewer (usually someone who won a local home brew competition) to craft their award-winning beer on the commercial equipment, which would then be offered in the commercial brewery's taproom. The amateur brewers enjoyed that they could receive feedback on their creation. For example, PRO5 supported AB10, a winner of the local home brewing competition, to make his 


\section{PRO2}

"I gave [a talk] about getting into the industry. If I am at a beer dinner, I get up and speak...or do Q\&A...Sometimes I will Skype with groups in Florida, or groups in California We talk about beer and brewing and the history, where it's coming from in [State] and where it's coming from at [his brewery]. We talk about sensory evaluations of beers and stuff like that. I've done many of those." (Male, brewing professionally for $20+$ years)

\section{PRO3}

"We [PRO3 and his professional brewer friends] would judge [the home brew competition] and then whoever won that competition, they'd come in for a brew day, and we'd brew it on our 30 barrel system."

(Male, brewing professionally for $5+$ years)

\section{AB10}

"It's helpful to get feedback from [ the professional brewer] judges, people who professionally taste beer." (Male, brewing as an amateur for $5+$ years)

\section{PRO5}

"I do the bulk grain ordering for them on a monthly basis... I don't upcharge so they can buy in bulk sacks and save a lot of money."

(Male, brewing professionally for $8+$ years)

\section{AB4}

"[In response to the bulk grain ordering] We get the benefits and we get the access to brewer's prices for grain.. it's helpful."

(Male, brewing as an amateur for $15+$ years) beer using the professional system. While AB10 was enjoying the collaboration with PRO5, he also gained a deeper understanding of the brewing process and managed to craft more creative beer styles.

\section{Training}

The training opportunities that professionals afforded to amateurs supported the amateurs' to gain new skills in brewing. Like PRO2, he often passed on new things that he learned from an annual nationwide brewing conference to the amateur brewers. For example, he sometimes hosted online workshops where he walked through and discussed brewing techniques with amateur brewers.

In another example, PRO3 mentioned that he often served as a judge of amateur home brewing competitions and provided feedback to non-professional contestants. As an amateur entrant, AB10 mentioned that the feedback provided by the professionals helped him to understand where he excelled and where he could improve. In both cases, the professionals supported amateurs to learn new things about their shared domain of interest, which helped the amateurs craft beer in novel and interesting ways.

\section{Obtaining Supplies}

As professionals, our participants mentioned that they had access to resources that were difficult for amateurs to come by or expensive to purchase in small quantities. PRO2, PRO3 and PRO5 have volunteered to order beer-making materials (e.g. hops and malts) for local amateurs through their wholesale distributor. It not only saved the amateurs money, but it also gave them access to a wider assortment of ingredients (as described by PRO5). Amateur brewer, AB4, also echoed the advantage of getting resources through the professional. He could reap the benefit of wholesale prices for his home brew because his home brew club had a close relationship with PRO5. In this way, he could afford to experiment with new or interesting ingredients.

\section{CONCLUSION AND FUTURE WORK}

Our participants' stories demonstrate that support from professionals facilitates the amateur's creativity in many ways. Non-experts are able to utilize connections to expand their crafting skills, are inspired by mentorship and training to experiment with new styles, and have increased chances to produce innovative products through procurement of affordable supplies. Technologies to support creativity should leverage the unique strengths and assets (e.g. their connections, mentorship, teaching, and supplying materials) of the professionals. Furthermore, we encourage designers to consider all possible roles that one can play within a creative domain of interest and how that role can be enhanced to support innovative crafting. In the future, we will further investigate creative support in other communities of practice to determine if these findings can support creativity in other domains. 


\section{ACKNOWLEDGMENTS}

This work was supported by the National Science Foundation (\#1502176). We thank our participants.

\section{REFERENCES}

[1] Teresa M Amabile. 2018. Creativity in context: Update to the social psychology of creativity. Routledge.

[2] Brewer's Association. 2017. Study: 1.1 Million Americans Homebrew Their Own Beer. https://www.brewersassociation. org/press-releases/study-1-1-million-americans-homebrew-beer/

[3] Brewer's Association. 2018. Craft Brewer Defined. https://www.brewersassociation.org/statistics/craft-brewer-defined/

[4] Brewer's Association. 2018. Number of U.S. Breweries. https://www.brewersassociation.org/statistics/number-ofbreweries/

[5] Jeffrey Bardzell, Shaowen Bardzell, and Austin Toombs. 2014. now that's definitely a proper hack: self-made tools in hackerspaces. In Proceedings of the SIGCHI Conference on Human Factors in Computing Systems. ACM, 473-476.

[6] Barney G Glaser, Anselm L Strauss, and Elizabeth Strutzel. 1968. The discovery of grounded theory; strategies for qualitative research. Nursing research 17, 4 (1968), 364

[7] Tiffany Knearem, Xiying Wang, Jiaan Wan, and John M Carroll. 2019. Crafting in a Community of Practice: Resource Sharing as Key in Supporting Creativity. In Proceedings of the 2019 on Creativity and Cognition. ACM, 83-94.

[8] Austin L Toombs, Shaowen Bardzell, and Jeffrey Bardzell. 2015. The proper care and feeding of hackerspaces: Care ethics and cultures of making. In Proceedings of the 33rd annual ACM conference on human factors in computing systems. ACM, 629-638.

[9] Cristen Torrey, Elizabeth F Churchill, and David W McDonald. 2009. Learning how: the search for craft knowledge on the internet. In Proceedings of the SIGCHI Conference on Human Factors in Computing Systems. ACM, 1371-1380.

[10] Etienne Wenger, Richard Arnold McDermott, and William Snyder. 2002. Cultivating communities of practice: A guide to managing knowledge. Harvard Business Press.

[11] Etienne C Wenger and William M Snyder. 2000. Communities of practice: The organizational frontier. Harvard business review 78,1 (2000), 139-146. 